\title{
CHEMICAL-BASED INSPIRATIONAL THEORETICALLY LABORATORY EXPERIMENTAL TREATMENTS FOR SUGAR-MALABSORPTION DISEASES.
}

\author{
Ahmed Y. Azzam.
}

Undergraduate, Medical Student. October 6 University. Faculty of Medicine.

Article Info: Received 20 June 2019; Accepted 18 July. 2019

DOI: https://doi.org/10.32553/jbpr.v8i3.629

Address for Correspondence: Ahmed Y. Azzam, October 6 University. Faculty of Medicine.

Conflict of interest statement: No conflict of interest

\section{ABSTRACT:}

The process of glucose absorption inside the body is initiated in stomach like any type of micro-chemical nutrients but specially in , epithelial cells lining small intestine. though $\mathrm{Na}$ +/glucose cotransporter (SGLT1) electrochemically, other transporters and sometimes using intestinal polypeptides involved. Dysfunction of epithelial cells of small intestine, transporters or in malignant cases in, absorption intestinal polypeptides leads to a rare disease called Glucose-galactose malabsorption. In this disease absorption of sugar molecules is not done probably it's accompanied baby born genetic disease. Which leads to precipitation of large sugar molecules not absorbed? In other disease that called Hypochlorhydria. Which is lack of $\mathrm{HCl}$ production due Pernicious anemia, surgical operations in digestive system, H.Pylori, gastric bypass, VIPomas, Hypothyroidism, Radiations to GIT system and gastric cancer could lead to production of very small amounts of $\mathrm{HCl}$ which also in some cases ( Not All) has effect on absorption of sugar from gastric fluid. In this publication I'll focus more on Hypochlorhydria sugar-malabsorption side-effect in some patients who may suffer from it. In the other hand, I'll try to involve Glucose-galactose malabsorption disease but it will be limited in the experiments because, this disease is due to genetic mutations not due to gained pathological factors during life. In recent researches in highly accurate simulated chemistry lab in In-Vitro experiments to keep out from hazards reactions of real-life chemistry lab chemical medication experiments results. I've found that D-Gluconic acid when manufactured as sugar source instead of direct sugar has a very good effect for people who is suffering from sugar malabsorption caused of gastric fluid problems. It shown it's better ability to get soluble easily in the gastric pathway and stomach fluid. Acetic acid and Calcium acetate shown that they have good effect for Hypochlorhydria patients with sugar. They help on faster sugar absorbing and establishing sugar bonds before getting absorbed which makes it easier to digest. On the other hand Aluminum high doses shown that it may be a struggling source for people who suffer from gastric fluid problems like Hypochlorhydria so it's recommended to reduce and take care of taking doses of aluminum. For Glucosegalactose malabsorption disease patients. D-Gluconic acid can be used as a secondary-stabilizer disease reducer in addition to acetic acid for helping to break sugar bonds if the patient needed to get sugar source for emergency cases to make it easier for some mild cases to digest but, it can't be used for long time because it's not so much effective but it's a disease partial reducer for emergency sugar needed cases. It shown that it may help in some of mild cases severe cases aren't included yet in this experiment since it has no effect on them at most.

\section{INTRODUCTION}

The process of digestion of micro-nutrients substances like glucose, fructose, lactose ,aluminum, iron and calcium ...etc. is majorly done from gastric fluid and from pancreatic secretion is fullycompleted. In this article it's focused on gastric fluid station problems that may lead to some on absorption diseases. This article won't talk about the pancreatic secretion function it will be on gastric fluid disorders only. In a Virtual simulated high quality chemistry lab. 2 labs were divided for 2 experiments. For first lab it's for In-Vitro D-Gluconic acid experiments. 2 test was done in this section, it will show the importance role of D-Gluconic acid that might be grateful if developed and administrated with right dose for person under specialized doctor for treating sugar malabsorption diseases if the reason was in stomach region specially if it is from the gastric fluid or gastric cells like diseases mentioned in the abstract. In lab 2 in 7 tests. Simulation stomach acid fluid Is made. To test in it the problems of dissolving and absorption in gastric fluid station. In this second lab it is 
Ahmed Y. Azzam et al., Journal of Biomedical and Pharmaceutical Research

specially for recording the aluminum, calcium, and glucose absorption problems on patients of Hypochlorhydria disease and some of in patients on Glucose-galactose malabsorption. But ,to be honest on Glucose-galactose malabsorption this is not confirmatory, since the cause of the diseases isn't specified same for all persons due to the type of mutation of gene leading to this disease. But, in some cases it might be helpful.

\section{Materials and Methods.}

First Lab:

ml In-Vitro D-gluconic acid dose experiments : 25

Test 1: First In-Vitro Chemical Experiment

$37 \mathrm{C}$ temperature.-

On $200 \mathrm{ml}$ water $+50 \mathrm{~g}$ glucose / sucrose. -

Adding $10 \mathrm{ml}$ manufactured $\mathrm{HCl}$. -

Adding $100 \mathrm{ml}$ Water. -

Full sugar absorption.-

Absorption done in about 2 seconds.-

Test 2: Second In-Vitro Chemical Experiment

\section{C temperature. -}

On $200 \mathrm{ml}$ water $+50 \mathrm{~g}$ glucose / sucrose.-

Adding $10 \mathrm{ml}$ manufactured $\mathrm{HCl}$. -

Adding 25ml D-Gluconic acid. -

Increase in sugar content to $62.4 \mathrm{~g}$.-

Adding 150ml Water.-

Absorption done in about 1.58 seconds.-

\section{Results for Test 1 and 2:}

D-Gluconic acid $25 \mathrm{ml}$ in the second In-Vitro experiment has proven good effect on improving sugar-synthesis and sugar absorption.

In-vitro experiments has done In high quality virtual chemistry simulated lab. a test tube connect to another tube with connector thin tubes at 37C temperature. After adding pure manufactured $25 \mathrm{ml} \mathrm{D-Gluconic} \mathrm{acid} \mathrm{to} 50 \mathrm{~g}$ glucose in $200 \mathrm{ml}$ water solution with reaction with $10 \mathrm{ml}$ manufactured $\mathrm{HCL}$. The glucose solution content increased slightly about \%24.8 glucose content with \%1.26 faster glucose absorption compared to normal condition. The first lab experiments might be used with other medication yet for trying to cure or reducing Glucose-galactose malabsorption side-effects on the patient.

Second Lab:

:Simulated acid stomach experiments

Acid of stomach simulation ingredients :

50ml Water. -

$5 \mathrm{ml}$ Manufactured $\mathrm{HCl}$. -

$5 \mathrm{~g} \mathrm{NaCl}$ -

$5 \mathrm{~g} \mathrm{KCl}$.

\section{Test 1:}

Simulated stomach acid is made, but with limited source of $\mathrm{HCl}$ makes it simulation -for Hypochlorhydria disease.

$1 \mathrm{~g}$ of aluminum was added to the solution. -

$\mathrm{HCl}$ gradually decreased from $5 \mathrm{ml}$ to $1.7 \mathrm{ml}$ in 3 seconds.-

aluminum gradually fully dissolved. -

\section{Result 1:}

Aluminum high sources has direct decreasing effect on $\mathrm{HCl}$ on stomach acid on simulated Hypochlorhydria .

Note: High sources of Aluminum in food can be from food and supplements. Also cooking in Aluminum can increase the content in the food.

Test 2:

$1 \mathrm{~g}$ of aluminum was added to the simulated solution for Hypochlorhydria disease. -

$\mathrm{HCl}$ gradually decreased from $5 \mathrm{ml}$ to $1.7 \mathrm{ml}$ in 3 seconds.-

aluminum gradually fully dissolved. -

$1 \mathrm{~g}$ of aluminum was added again to the solution. -

$\mathrm{HCl}$ decreased from $1.7 \mathrm{ml}$ to $0.1 \mathrm{ml}$. -

$0.3 \mathrm{~g}$ of aluminum precipitated without dissolving.-

\section{Result 2:}

High aluminum dose from food or supplements without caring on amount for Hypochlorhydria patients may lead to more development for the disease in the patient.

Test 3:

2| P a g e 
The simulated stomach acid was added to a volumetric flask with limited amount of- $\mathrm{HCl}$ as a simulation for Hypochlorhydria disease. Connected to two small test tubes with a small glass pipette tube as a simulation for digestive pathway for food.

$2 \mathrm{~g}$ of aluminum was added to the first small tube. The second small tube $25 \mathrm{~g}$ of- glucose was added to it.

the sugar and aluminum were pumped same time in the simulated digestive- pathway.

As the two ingredients arrived to the simulated gastric fluid in the volumetric flask.- Dissolving started normally. But, after few seconds as $\mathrm{HCl}$ source is limited. $\mathrm{HCl}$ levels started gradually decrease by about $\% 65$. Since, there is no plenty amount of renewed $\mathrm{HCl}$ as in Hypochlorhydria disease.

Sugar dissolving was fine for few seconds, then after $\mathrm{HCl}$ gradually dissolved.- Some of sugar started to participate In the fluid instead of being dissolved or absorbed after the $\mathrm{HCl}$ mount decreased.

\section{Result 3:}

For Hypochlorhydria patients. Absorption of nutrients especially like what it's- dissolved In gastric fluid before diffusion as glucose or fructose is affect by aluminum high doses.

\section{Test 4:}

Simulated gastric fluid was added to volumetric flask. As a simulation for stomach -and gastric fluid in human.

a small tube with connected glass pipette to volumetric flask as a simulated pathway- for food from mouth to stomach .

25g Sugar (Glucose or Fructose), 2g aluminum and $10 \mathrm{ml}$ Acetic acid $\mathrm{CH} 3 \mathrm{COOH}$ were pumped into thesimulated pathway for food to the volumetric flask.

Glucose and aluminum levels were dissolved better condition in the gastric fluid -when Acetic acid was added.

\section{Result 4:}

Administration of $\mathrm{CH} 3 \mathrm{COOH}$ Acetic acid with food into the stomach may help some patients with better absorption for sugar or food.
Note: Administration of any medication in this publication is still under-testing. It might be unsuitable for all patients of Hypochlorhydria or Glucose-galactose malabsorption due to genetic variations and origin and history of the disease with the patient.

\section{Test 5:}

Simulated gastric fluid was added to volumetric flask with limited-source of $\mathrm{HCl}$ - As Hypochlorhydria disease.

a small tube with connected glass pipette to volumetric flask as a simulated pathway- for food from mouth to stomach.

$10 \mathrm{~g}$ glucose, $50 \mathrm{ml}$ water, $2 \mathrm{~g}$ calcium and $10 \mathrm{ml}$ acetic acid were pumped. -

during pumping, calcium and acetic acid formed Calcium Acetate substance. -

when the pumped substances arrived to the volumetric flask, it started dissolving- normally without any negative affection on $\mathrm{HCl}$ levels on the flask. And glucose level dissolved normally.

\section{Result 5:}

Calcium Acetate shown that it has guardian function from calcium amount for limited amount of $\mathrm{HCl}$ in the flask.

Note: Calcium in most of past-researches were applied that it's stimulatory for gastric secretion . But, in a new research, showed that it's not true it all times. There's some pathological or pharmacological factors that can convert it from stimulatory to inhibitory. This test shows that might be in some malabsorption patients (Not only sugar-malabsorption diseases) Calcium can be little-inhibitory for gastric secretion for $\mathrm{HCl}$ but, this is not fully confirmed yet since, it's In-Vitro chemical experiment.

\section{Test 6:}

Same like above, but aluminum was added to the ingredients.-

\section{Result 6:}

Unfortunately, it didn't help. $\mathrm{HCl}$ levels started dropping like past $\mathrm{HCl}$ dropping results. So, aluminum substances aren't effected by guardian effect of Calcium Acetate like test 5. 


\section{Test 7:}

Simulated gastric fluid was added to volumetric flask with limited $\mathrm{HCl}$ source as- past tests. As a simulation for stomach and gastric fluid in Hypochlorhydria disease.

A small tube with connected glass pipette to volumetric flask as a simulated pathway- for food from mouth to stomach

$25 \mathrm{~g}$ glucose, $50 \mathrm{ml}$ water, $2 \mathrm{~g}$ calcium and $5 \mathrm{ml}$ acetic acid diluted with $50 \mathrm{ml}$ water- were pumped in the pathway. During pumping, calcium and acetic acid formed calcium acetate substance -

when the pumped substances arrived to the volumetric flask, the difference between -test number 5 and this test Is that, levels of $\mathrm{HCl}$ started gradually decrease in the flask. This is because diluted acetic acid wasn't strong enough for this case. In mild Hypochlorhydria administration of diluted Acetic acid may lead to results like test 5 but this is not confirmed yet.

All of the above in test 7 was done in different test but with concentrated $25 \mathrm{ml}$ - Acetic acid.

The result was overwhelming dissolving, but this won't be useful in human. Since, -mucosa layer would be damaged easily due to highly acidic content.

\section{Result 7:}

Diluted acetic acid administration for average Hypochlorhydria patients isn't useful. -

Concentrated Acetic acid is overpowering dissolving result. But useless in humans -because it can damage Mucosa layer due to highly acidic content.

\section{Conclusion:}

In this article, those were new results in sugarmalabsorption diseases that is caused by gastric fluid or stomach lining cells. Administration of the mention substances in the experiments is still under-testing and not finally confirmed. It needs to be completed by specialized researchers in digestive field to check the administrations and the dose of the substances used. Those experiments might be helpful if developed under specialized researchers and may lead to formation of new medications for those diseases.

\section{References:}

1. National Center for Biotechnology Information (US). Genes and Disease [Internet]. Bethesda (MD): National Center for Biotechnology Information (US); 1998-. Glucose-galactose malabsorption.

2. Lihong Chen, Biguang Tuo, and Hui Dong. Regulation of Intestinal Glucose Absorption by Ion Channels and Transporters. NCBI. DOI: 10.3390/nu8010043. •

3. van der Voet GB. Intestinal absorption of aluminium. Ciba Found Symp. 1992;169:10917; discussion 117-22..

4. Fatima R, Aziz M. Achlorhydria. [Updated 2018 Dec 2]. In: StatPearls [Internet]. Treasure Island (FL): StatPearls Publishing; 2019 Jan..-

5. U.S National library of medicine. National center for biotechnology information. DGluconic acid. PubChem CID:10690.

6. I Puscas 1, M Coltau, M Baican, G Domuta, A Hecht. Calcium, Carbonic Anhydrase and Gastric Acid Secretion. Physiol Res, 50 (4), 35964. U.S National library of medicine..

7. National institute of diabetes and digestive and kidney diseases. Your digestive system \& how it works. 2017.

8. Ciba Found Symp Greger JL. 1992;169:26-35; discussion 35-49. Dietary and other sources of aluminium intake.

9. Wright EM, Turk E, Martin MG. Molecular basis for glucose-galactose malabsorption. Cell Biochem Biophys. 2002;36:115-121. doi: 10.1385/CBB:36:2-3:115.

10. Barone $S$, Fussell $S L$, Singh $A K$, Lucas $F, X u J$, Kim C, Wu X, Yu Y, Amlal H, Seidler U, Zuo J, Soleimani M. Slc2a5 (Glut5) is essential for the absorption of fructose in the intestine and generation of fructose-induced hypertension. 